\section{Is taking a history outmoded? Why doctors should listen to stories instead}

\author{
John Launer
}

The last time I was a hospital in-patient, three medical students approached me and asked if they could take a history from me. I agreed. Standing some distance from my bed, they began to fire questions at me: "What is your date of birth? What is the problem that brought you into hospital?" I told them, and they launched straight into the systems inquiry I remember being taught myself at medical school. I stopped them to explain as gently as I could that I was a medical educator and wondered if they would allow me to suggest a different approach. I asked them to fetch some chairs and sit close to my bed. Once they did so (nervously, because they believed there might be a regulation against this) I proposed a different opening question: "Would you mind telling us about yourself?"

Most doctors, and certainly all educators, will recognise what I was trying to do. I wanted them to lessen their distance from me both physically and emotionally. I hoped they might engage with me as a person and not relate solely to my demographic data, symptoms or pathology. I was influenced by working for around thirty years in general practice, where most patients would regard their style of inquiry as abrupt and alienating. I was also guided by schools of thought like patientcentred medicine, ${ }^{1}$ relationship-centred care $^{2}$ and narrative-based practice. ${ }^{3}$ From all these perspectives, I knew that a more sociable way of interacting with patients and their stories is essential not only for building trust but for eliciting the information that doctors need for diagnosis, treatment and healing. ${ }^{4}$

The experience led me to two conclusions. The first is that training in history-taking does not seem to have altered substantially, at least in its impact, for over thirty years, and possibly much longer. Of course, students do now receive some education in communication skills, and most have early exposure to working in the community. Yet despite this, the role models they see in hospital, the pressure of exams, and no doubt other factors, evidently still encourage them to speak with patients in traditional and artificial ways, focusing on the disease rather than the person, their context or their concerns. This led me to my other, more radical conclusion: perhaps we should now abandon the idea of taking a

Correspondence to Dr John Launer, Associate Editor, Postgraduate Medical Journal, London, UK; johnlauner@aol.com history altogether and talk only about listening to people's stories.

\section{IMPRESSIVE RESEARCH}

I found support for this idea recently from some impressive research on patient consultations carried out by a team in Marburg, Germany. ${ }^{5}$ They analysed 132 consultations in general practice that each included an episode where the doctor needed to establish a diagnosis. Contrary to common belief, the doctors did not actually conduct an inquiry of the kind taught in medical schools. Instead, they carried out a process which the researchers astutely characterise as 'inductive foraging'. This involves starting with an open invitation such as 'What can I do for you today?' and following this with brief prompts directly linked to the patient's narrative such as 'For how long' and 'Which symptoms are most disturbing?' Other prompts include non-verbal ones like nodding, but all without interrupting the patient's flow. According to the research, this phase in the consultation, which lasts up to $3 \mathrm{~min}$, yields an average of 4.5 useful cues that allow the doctor to formulate and offer a diagnosis ('Oh yes, you've got shingles'). The doctor or patient then move the conversation on to other business such as a physical examination or a discussion of treatment.

This study confirms several things. It demonstrates that experienced doctors may not take a history at all in the conventional sense. They gather information by allowing the patient's narrative as full a flow as possible. They build up their hypotheses and diagnoses by accumulating cues in the natural order in which they emerge. ${ }^{6}$ The most important aspect of the process, as the authors emphasise, is that the patient can become an active participant in the diagnostic process rather than a mere object of scrutiny. This behaviour accords with the aphorism that is usually attributed to William Osler (although it does not appear in his writings): 'Listen to the patient, who is telling you the diagnosis.' The doctors in the study were GPs, but I imagine that many hospital specialists will also recognise inductive foraging as something they do intuitively, even if this is different from what they were once taught. It is both friendlier and more efficient than the deductive, problem-solving approach that is still widely taught as the core principle of clinical reasoning.

\section{GIVING NOT TAKING}

Could we teach medical students to work in this way from the outset of their training? An objection to doing so would presumably be that they must learn to walk before they can run, and that no doctor could know what to listen for in a patient's presentation before having first been trained in a litany of direct questions to suit a range of conditions. Against this, I would pose the question: why are we still teaching a form of interrogation that objectifies patients, constrains open expression, may limit the information we obtain, and that doctors will need to unlearn once they become established?

Listening to the patient's story is not some politically correct or sentimental add-on to medical conversations. It is the essence of medical practice. The Greek word anamnesis, formerly used to describe the patient's narrative, means 'recalling to mind' and suggests an act of recovery and re-creation by the patient, with the doctor acting as facilitator. It implies 'giving' one's attention to the patient rather than 'taking' something away. Abandoning the notion of taking a history and replacing it with the idea of listening to the story could be a vital step in creating more humane and equitable interactions in medicine.

\section{Twitter John Launer @JohnLauner}

Funding The authors have not declared a specific grant for this research from any funding agency in the public, commercial or not-for-profit sectors.

Competing interests None declared.

Patient consent for publication Not applicable.

Ethics approval This study does not involve human participants.

Provenance and peer review Not commissioned; internally peer reviewed.

(c) Author(s) (or their employer(s)) 2022. No commercial re-use. See rights and permissions. Published by BMJ.

$$
\text { A Check for updates }
$$

To cite Launer J. Postgrad Med J 2022;98:236.

Postgrad Med J 2022;98:236.

doi:10.1136/postgradmedj-2022-141516

ORCID iD

John Launer http://orcid.org/0000-0003-3833-9352

\section{REFERENCES}

1 Stewart M, Brown JB, Weston W. Patient-Centered medicine: transforming the clinical method. 3rd ed. Abingdon: CRC Press, 2013.

2 Beach MC, Inui T, Relationship-Centered Care Research Network. Relationship-centered care. A constructive reframing. J Gen Intern Med 2006;21 Suppl 1:S3-8

3 Launer J. Narrative-Based Practice in Health and Social Care. Abingdon: Routledge, 2018.

4 Jagosh J, Donald Boudreau J, Steinert Y, et al. The importance of physician listening from the patients' perspective: enhancing diagnosis, healing, and the doctor-patient relationship. Patient Educ Couns 2011;85:369-74

5 Michiels-Corsten M, Weyand AM, Gold J, et al. Inductive foraging: patients taking the lead in diagnosis, a mixedmethods study. Fam Pract 2021:cmab144.

6 Haidet P, Paterniti DA. "Building" a history rather than "taking" one: a perspective on information sharing during the medical interview. Arch Intern Med 2003;163:1134-40. 